traces of internal structure, which induce him to compare them to polygastric infusoria. In the interior are rounded sacs, which he considers analogous to stomachs ; and in addition, there are two points upon the surface which he considers to represent a mouth and anus. Mr. Owen, afer a careful examination of these animalcules in the Lion, could discover a granular internal structure only, without a trace of the high organisation seen amongst infusory animals.

Wagner has traced the development of the spermatozoa in the male fluid, and has found their stages very similar to the production of the female ovum. Their existence, as distinct animals, ought at once to be rejected, they resemble more closely in the animal economy the moving particles of pollen in the vegetable kingdom.

Excepting during the breeding season they are not found in the semen of some animals, as in the Insectivora, smaller Rodentia, and Passerine birds. In the Sparrow the testis at the end of winter is found to be full of small cells, which contain granules; these cells gradually disappear, and the granules arrange themselves in long filamentary threads. In this disposition they bear some analogy to the globular structure of the ultimate filaments of muscular fibre.

If, now, we reflect upon the close similarity which exists between the ova of all species of animals, and at the same time upon the great diversity in the form of the spermatozoa, we should be disposed to look upon the latter as the essential principle upon which the difference of character of the species will depend; and at the same time regard the ovum, like the seed of the plant, as the mere nidus in which the necessary changes are effected, rather than as containing within itself all the parts essential to its perfection.

\section{ON ACUTE RHEUMATISM.}

By David D. Davis, M.D., Professor of Midwifery in University College, London, \&c. \&c.

Mr. EDrtor:-In consideration of the very cold season, which has paid us a somewhat earlier visit than usual, I have to request your permission to withdraw, or, at all events, to postpone the publication of $\mathrm{my}$ second paper on natural labour, , in favour of the following contribution on acute rheumatism.

It happened that many years ago, before I knew any thing of medicine, $I$ became more than ordinarily interested in the issue

* See Lancet, vol. i., 1840-41, p. 329. of a severe case of acute rheumatism. A fellow-student, my late excellent but unfortunate friend, + Dr. Lant Carpenter, of Bristol, was withdrawn from the competitions of the public schools of Glasgow College, in consequence of his becoming the subject of the disease, on which it is my intention to make a few practical remarks on the present occasion.

As an intimate friend of the young patient during two or three previous years, I had almost daily opportunities of noticing what appeared to me most remarkable in the pro. fessional management of the case; but as I had not then commenced my medical studies, I, of course, presumed not to judge of the mierit of the mode of treatment adopted. My young friend was attended professionally by a junior hospital surgeon of some reputation in the city of Glasgow. That gentleman some years afterwards became a graduate either of the university or of the faculty of physicians and surgeons of the same city. He was decidedly, even then, esteemed a surgeon of great ability and of greater promise. My friend's case was placed exclusively under his care. Its violence and long duration proved a source of much sorrow and sympathy to his intimate friends, whilst its issues on his own sessional studies proved most unfortunate to himself. What I principally recollect of it now was, that the patient was bled to quantities of from eight to twelve ounces at a time, repeatedly in the course of a week, and for many weeks in succession; and that a packet of powders, accompanied by three or four draughts, which from their effects must have been sudorific medicines, were sent to his lodgings daily during the greater part of the remainder of the session of college; but he was not able during that session to appear in the schools again.

What I have further to remark upon this case, I shall reserve for notice when I come to speak of the treatment which I shall feel it my duty to recommend for adoption in cases of acute rheumatic fever. In the mean time, I have to place before my readers a succinct enumeration of the principal fact 3 and phenomena of the malady.

Acute rheumatism is frequently, if not generally, called rheumatic fever, or acute rheumatic fever, in the common language of this country. This is the form of rheumatism to which I purpose to call the attention of my readers in the present contribution. The term rheuma means an affiux to a part, or, as the case may be, a defluxion from another part. Hence rheumata and catarrhs, as expressive of movements of fluids to and from parts, were used by the Greeks as very nearly

+ My valued friend fell overboard, and was lost, while performing a voyage by sea for the benefit of his health. 
equivalent terms. As applied to gout and rheumatism, they were intended to intimate the belief that those maladies were the result of a morbid afflux of a supposed humour or fluid to the part or parts affected. We do not find our modern distinction between gout and rheumatism insisted upon, or even recognised, in the writings of the ancients. The term arthritis was the designation made use of to express all painful diseases of the joints.

Modern nosologists have placed acute rheumatism in the class of pyrexial or febrile diseases, and Cullen has placed it, moreover, in his order of phlegmasia or inflammatory fevers. He defines it to be " a disease derived from an external and generally from a known cause; accompanied by pyrexia, pain of the joints following the tracts of the muscles; affecting the knees and the other larger joints more frequently than those of the feet and hands : it is increased by external heat."

This writer recognises chronic rheumatism as a consequence of the acute affection, and gives it the subsidiary designation of arthrodynia. Acute rheumatism is necessarily accompanied, otherwise it would be a misnomer, by a more or less constitutional disturbance. In common with all the diseases of its class, it commences with chills or shiverings, which are succeeded by increased heat, a more frequent pulse, thirst, loss of appetife, and prostration of strength.

Acute rheumatism is a disease principally of cold countries and seasons, and in this country especially : of the colder months of the year, the months of December, January, February, March, and A pril, ordinarily producing, according to Dr. Haygarth's tables, as many cases of the malady as all the other months of the year together. But different years may have the effect of greatly diversifying in this respect the results of climates and seasons. It was ascertained, for example (see the "Gazette de Sante" for 1818), that a greater number of cases were received into the Parisian hospitals in the months of September, October, and December, than during any other three months of the year. Of late years, I have observed in England that our spring months of March and April have been remarkably productive of severe pleurisies and acute rheumatic fevers.

From Dr. Haygarth's accurate tables, we arrive at the conclusion that acute rheumatism is occasionally a disease both of older and younger persons than is commonly supposed. It affects all ages from below five to above sixty. More frequently from the age of five to thirty, but most frequently from that of fifteen to twenty years old. But statistical accounts on subjects like the present must obviously very greatly vary in different countries and seasons. We accordingly find the following results reported of the arlmissions of cases of acute rheumatism into the Hôpital de la Charité by M. Chomel. Out of serenty-three patients, subjects of acute rheumatism, thirty-five had been seized by it between the ages of fifteen and thirty; twenty-two between those of thirty and fortyfive; seven between those of forty-five and sixty; seven after the sixtieth year; two only before the fifteenth year, viz., one at the age of eight and the other at the age of nine years.

Of the Sex most predisposed to Acute Rheumatism.- Hoffmann, if he may be depended upon, for he is not always correct in his diagnosis between gout and rheumatism, has expressed his opinion somewlat positively, other things being equal, that women are more subject to acute rheumatism than men. For myself, I am greally disposed to prefer, on this part of the inquiry, the evidence of Dr. Haygarth to that of the more antiquated report of the German physician. What then does Dr. Haygarth say on the subject? He states in his tables that more males are attacked with acute rheumatism than females, in the proportion of ninety-eight of the former to seventy-three of the latter, or nearly as four to three; probably, he adds, because men are more exposed to cold and rain than women. On communicating this fact to an intelligent physician who had resided for several years at Rotterdam, that gentleman made the following remark: "What confirms your idea is, that in Holland rheumatic fever among females is a comparatively rare disease ; for, although the air is extremely moist, the Dutch women are much more domesticated than the women of this country, and their dress much warmer."

Of the Causes of Acute Rheumatism.-Dr. Barrow lays great stress upon plethora, as being a principal circumstance of predisposition to acute rheumatism; and hence, according to him, the greater liability of young people of both sexes to become the subjects of it than persons of middle or of more adranced age. I doubt how far I can accede to this assumption. Persons of either age, in limited or destitute circumstances, are not likely to become over plethoric; but if living in comparative ease and comfort in their several stations, althongh engaged in productive and eren moderately laborious occupations, the man at forty and fifty, other things being equal, is more frequently the subject of overfulness of the sanguiferous system than the youth of fifteen, or even the young man of thirty or five-and-thirty. It would therefore, perhaps, be more correct, in fact, to refer the predisposition contended for to the infiuence of age at once, that is, to the age of an earlier period of life; without assuming a doubtful or accidental accompaniment of that age as being necessarily the infuential principle of the diseased action. We may easily understand why all the tissues interested in acute rheumatism should be more susceptible of the actious of the disease in early than in more adranced life. 
The sanguineous and sanguineo-choleric temperaments are, upon the whole, more disposed to this malady than the average of any of the other temperaments. It has, moreover, been supposed that there is a predisposition in families to the disease, and this may really be very true, by reason of different members of the same families being the subjects of similar organisations. I am myself inclined to the opinion, that persons endowed with more than ordinary excitability of the heart and arteries, and consequently with more active powers, both of mind and body, are more frequently attacked by acute rheumatism than persons of listless and phlegmatic habits. The sameobservation applies to persons of delicate complexions and fine textures of skin in preference to persons of coarse textures of skin and of swarthy complexions; but the exceptions to these rules are very numerous, it being a fact that the occasional causes of rheumatism are more frequently the actual and determining causes to it, than all the predispositions to it put together.

The occasional causes of this malady are few and simple, and reducible to a union of two principal influences, viz., cold and moisture. Cold, by its intensity or long duration, it is well known, is productive of the severest forms of the disease; but when moisture is added to a simply cold atmosphere, however intense, the effect of the united influence is prodigiously enhanced and multiplied. Exposure to sudden varieties, and especially to sudden reductions of temperature, whether of parts or of the whole surface of the body, is, without exception, the occasional cause of the disease. If we analyse any list of occasional causes of acute rheumatism which we may meet with in our ordinary reading, they are all resolvable to accidental exposures to cold and moisture, as to damp rooms, damp beds, accidental exposure of our persons in heated states of the body to immersions in the sea and in rivers, or sitting subsequently to such accidents in wet clothes, sitting in wet shoes and stockings, \&c.; in short, it is cold long applied, or intense cold applied for a shorter duration of time, or some of the endless combinations of cold and moisture, that really are the most frequent occasional cause or causes of acute rheumatism. I have seen drunkenuessenumerated among the occasional causes of the disease, but this cause can only be said to operate indirectly, in consequence of the frequent liability to the action of cold to which the unfortunate habit in question exposes its victims. It has also been asserted, that sudden acts of violence, productive of contusions, lacerations, and sprains, have ever and anon operated as occasional causes of acute rheumatism. Without recollecting an example in illustration of such a point, I can well suppose the possibility of it, especially if acting concurrently with a state of great predisposition to the disease.

The occasional cause having been applied under any of its usual modifications, it sometimes happens that the disease shall remain suspended in the system for a day or two, without manifesting its proper character of a severe pyrexia. To this state of suspension of the malady, Dr. Haygarth gave the designation of the latent period in the way of analogy to what he had previously called the latent period of infectious diseases. Out of twenty-one cases, only four exceeded the period of forty-eight hours between the application of the occasional cause and the sub. sequent attack of the acute disease. "On this subject," he observes, " the shortest time noted is half an hour, but the cause and effect are sometimes connected together, without an interval of perfect health." The ordinary phenomena which usually precede or acconpany the invasion of the other phlegmasix, are found in like manner to usher in the attack of acute rheumatism, viz., lassitude; a sense of soreness of different parts of the body ; much prostration of strength, with an unusual depression of the spirits; loss of appetite; alternate chills and flushes; quickened pulse; thirst, and incipient pyrexial disturbance follow each other in the train of symptoms; in the course of twenty or thirty hours the local or arthritic phenomena present themselves: these are pain, and occasionally some redness in one or more of the larger joints, as the knees, shoulders, hips, elbows, ankles, wrists, but much less frequently the toes or fingers. When perfectly quiet, which is seldom the case, the patient may be observed to be com. paratively easy, but on the least movement an agonising pain is propagated along the muscles and their tendinous sheaths from one joint to another; the seat of the diseased action is rapidly shifted from joint to joint, and even, sometimes, from one limb to another, with much apparent caprice and irregularity for an indefinite period of time; the pain and its accompanying pyrexia, if not speedily subdued by vigorous practice, becomes tediously protracted, and eventually established for weeks or months. During the height and severity of the disease, the fever is ordinarily attended with much heat of skin, which is very distressing to the sensations; great impatience of all positions of the body, but, at the same time, with an almost total inability to obtain relief by any change; the local pains are intense and harassing during the day, and the days are chased away one after another by restless and sleepless nights; the high phlogosis of the disease is attended, moreover, with urgent thirst, and a constant indulgence in the use of aqueous and other diluent drinks, to make up for the rapid escape of fluids which takes place by profuse perspiration from every part of the surface of the body; the tongue is of a whitish-yellow colour, sometimes slightly loaded and smooth, and at other times more smooth than either furred or loaded; the state of the bowels is that of great tardiness, and in many cases of 
obstinate constipation; the pulse of rheumatic fever is more frequently characterised by strength and volume, than by great hardness or any extraordinary frequency, the range of its rhythm varying between ninety and a hundred and ten strokes in a minute; the nocturnal exacerbations of the malady are frequently accompanied by severe headaches, with a tendency to delirium, followed by slight morning remissions of the profuse and clammy perspirations of the previous hours, but without a corresponding reduction of the temperature of the skin, and often without any material mitigation of the constitutional or even of the local symptoms; the urine is at first scanty and high-coloured, depositing, in the progress of the disease, a copious lateritious sediment; the blood, when drawn from the arm, exhibits the usual character of an intensely-inflammatory disease ; upou cooling, it throws upon the surface a thick coating of lymph, which is often much cupped and fringed at the edges; the expression of the features is always indicative of intense pain, and in a class of cases to be presently noticed, of extreme anxiety and profound distress and despondency.

In this way, acute rheumatism, when subjected to the treatment which we have occasionally seen adopted, runs a course of several weeks, and occasionally of months; after the first fortnight or three weeks the severity of the pyrexia usually declines, and the final termination of the complaint takes place by more or less obvious crises, by some of the secerning emunctories of the system, as by the kidneys, the bowels, or skin, but in a greater number of cases it terminates by a gradual and scarcely observable subsidence of the symptoms.

Acute rheumatism lays the foundation of great susceptibility to future attacks of the disease, and every repetition of it adds to the damage first sustained by the constitution.

Independent of this consideration, rheumatic fever is a less dangerous disease than pleurisy, or some other visceral inflammations; but, by its translations to the heart, to the lungs, to the brain, and to other vital organs, which happity are not of very frequent occurrence, it becomes more decidedly dangerous even to life than any of the other phlegmasiæ. These terrible modifications of rheumatic fever were scarcely known to the profession before the latter part of the last century; when, about the year 1788, "Dr. David Pitcairn began to remark, that persons subject to rheumatism were attacked more frequently than others with diseases of the heart." Subsequent experience confirming the truth of his observation, he at length concluded that the two diseases might probably depend upon a common cause. He communicated what he had observed to several of his frieuds, and also to his pupils at Bartholomew's Hospital, of which he was then one of the physicians. About this period, or soon after, inflammatory affections of the heart came to be designated summarily as cases of rheumatism of the heart. The first published notice taken of Dr. Pitcairn's observation we find recorded in the second edition of Dr. Baillie's " Morbid Anatomy," published in 1797 ; since that period the translations of acute rheumatism to the interior and more vital organs of the body have been better and more generally known to the profession in consequence of several excellent essays and papers which have been published in this country and abroad by not a few very practical and competent writers. At the head of this list should be placed next in order to Dr. Pitcairn, the name of Dr. Charles Wells, late physician to St. Thomas's Hospital. The communications of that gentleman, as published in the third volume of the transactions of a society for the improvement of medicine and surgery, went far to establish the pathology of what was designated rheu. matism of the heart. To Dr. Wells's name may be added those of Sir David Dundas, Drs. Odier and Matthey, of Geneva; Drs. Pemberton, Marcet, and Bateman, and more recently that of Dr. James Johnson, together with six or eight very able correspondents of the latter gentleman, not to mention many other contributors of cases on the same subject in the medical journals of London and Edinburgh, who, since the time of Dr. Wells, have extended our knowledge of the metastasis of rheumatic fever; although I regret to add, that they do not appear to me to have greatly extended our control over those most anomalous and terrible modifications of the disease.

Much difference of opinion prevails as to the seat of rheumatic inflammation. The arthritis of the ancients, whether gout or rheumatism, for,--as already stated, they recognised not the distinction between gout and rheumatism,-obviously expressed their belief of its being an arthritic inflammation, a painful disease of the joints, that is, probably of all the constituent tissues of the joints. It has been considered by others as being painful and inflammatory affections of the muscles and ligaments connected with the joints, and propagated uncertainly from the joints first affected to other joints, or migrating from those joints to more distant articulations, or to remote limbs of the patient, but frequently without any very observable selection of routes or tracts of transit between part and part. Many writers have considered the white fibrous tissues, including all the ligaments and investing membranes, both of joints and of soft structures, of whatever denomination, as the seat of rheumatic inflammation. The French distinguish rheumatism into muscular and synovial, as also rheumatism of the periosteum, together with many other varieties of the disease founded upon divers hypothetical notions of its presumed occasional causes. In Dr, Parr's 
opinion (see Johnson's Dissertation, Appendix, p. 244), it is proximately an affection of the coats of the arteries. It is really not easy to determine which of the tissues now enumerated is most frequently the seat of acute rheumatism; and nearly as difficult to say which of them may not, in any given case, seem most interested in the symptoms attendant on the disease.

The inflammation of rheumatic fever is remarkable for several peculiar and characteristic attributes. It is erratic and migratory. It does not terminate in suppuration, or, at all events, so rarely, that the fact of such a termination has actually been denied; it remits, becomes suspended, and then returns more frequently and with more violence than any of the inflammatory fevers that we are acquainted with. It is also considered less positively subject to the control of active remedies than any of the phlegmasia. But is this latter opinion founded in fact, and on the evidence of competent experience? I think not; and I feel it my duty to place before the profession the long-neglected claims of the cinchona bark as a remedy for acute rheumatism, which has never been duly attended to, nor fairly and dispassionately estimated.

Let me now invite my reader's attention to the sequel of Mr. Carpenter's case, which I made introductory to the present contribution. It served greatly, as already intimated, to repress my eagerness as to the value and power of the art which I was then about to make my profession. I, nevertheless, proceeded to its study, and in due time took my degree in medicine. During the several years of my professional studies, including an assiduous hospital attendance of three years, the reader may well suppose that $I$ was not inattentive to the treatment of any cases of acute rheumatism which came before me. But I must confess that my experience of hospital attendance served but little to increase my confidence in the efficiency of the treatment of that malady, which from day to day I saw adopted. After the lapse of about seven years, subsequently to the time at which we have now arrived, $I$ became settled as a physician at Sheffield, and appointed one of the physicians to the General Infirmary, in the immediate neighbourhood of that town. It happened that soon after my appointment, I saw in the "Medical and Physical Journal" of that period, an announcement of Dr. Haygarth's "Clinical History of Acute Rheumatism." I lost no time in procuring a copy of it; and in my then state of predisposition to feel an interest in any proposed novelty in practice, which might have the treatment of acute rheumatism for its object, I read it with extreme surprise and satisfaction. In short, I read it many times over, and studied its important tables with very great care. In the course of the immediately following winter,
I determined to make its principles available for the treatment of the first case of acute rheumatism which presented itself at the hospital. An admiring pupil of Dr. Robert Cleghorn, who was a principal physician during my attendance at the Royal Infirmary of Glasgow, and who was a most excellent and vigorous practitioner, I considered not myself as belonging to the class of students who had been carried away by the fascinations of the Brunonian system; and under impressions of a somewhat contrary tendency, it had become one of my earliest convictions that the bleedings which I had seen adopted in the treatment of acute rheumatism, had been almost invariably too scanty to produce a proper impression upon a disease so formidable in its onset, as I considered that to be. Upon the perusal of Dr. Haygarth's work, I felt myself compelled to yield to his argument; although $I$ ventured not to adopt it in a single case without a previous ample general bleeding. For the efficiency of this part of the treatment, I was under great obligation to Mr. Ernest, now Dr. Ernest, then, as now, the estimable house-surgeon of the Sheffield Infirmary. As soon as the patients were allotted, and the arrangements for the admissions of the day were finished, it was our practice to bleed the subjects of acute rheumatism freely, and without loss of time. If any fainting followed, it was not considered a subject of regret. When the fainting was well over, an emetic powder, consisting of tartarised antimony and powder of ipecacuanha was forthwith administered; and the patient was supplied with barley-water or thin grnel, ad lihtum. This was all that was usually done for the first day's treatment. The emetic was given not as an antimonial, in correspondence with the common notions of practice then prevailing, but, first, as an emetic, an emptier and cleanser of the stomach; and, secondly, as a febrifuge, or a subduer of febrile action. On the morning of the following day the patient was well purged with calomel and jalap. The dose was generally five grains of the former to a scruple of the latter. Beyond this I really do not recollect what was pre. scribed for the second day's treatment, but I well remember that on the subsequent morning we began to administer the bark. Our form of this medicine was exclusively the best yellow bark, in powder; and the quantity ordered was in some cases a scruple, and in others half a drachm, according to circumstances, every three or four hours. This was the ordinary routine of the practice. It generally happened that the patient was much better from the first full bleeding; and better still in consequence of the emetic; whilst there appeared no reason to doubt that the active purgative answered an excellent purpose by thoroughly emptying the bowels. The joints or parts most severely tormented by the pains incident to the diseasc, were 
referred to the nurses to be well leeched with- / one less fortunate exception, which, in conout delay. The number of leeches ordered on these occasions, were proportioned to the phlogosis of the particular case. The number ordered for a first application, might vary between fifteen and five-and-twenty. If not inconvenient from its position, the leeched joint or limb was ordered to be immersed in lukewarm water, to promote the bleeding from the leeches, and to mitigate the patient's sufferings, which I am quite sure it very much promoted. Our patients were generally hale and strong young men, "agricultural labourers," brought to us from the surrounding country to the extent of many miles, together with a smaller proportion from the manufactories of the town and immediate neighbourhood of Sheffield. They were all subjected to the treatment now detailed, as to its general principle; and $I$ do not recollect that we encountered a single case of failure, much less of a seriously inconvenient result of any kind, from the practice adopted during any period of my subsequent connection with the Sheffield General Infirmary. A second general bleeding was now and then indicated, bat not frequently; and when it was considered necessary, we were content with the abstraction of a much smaller quantity of blood, viz., a quantity in many cases short of twenty ounces. We attached considerable value to the local bleeding by leeches; and this practice was repeated from time to time, as might be indicated by the amount of the pain, heat, swelling, or appearance of inflammation of the parts affected. Our patients were admitted and dismissed on Fridays. It sometimes happened that my patients, the subjects of acute rheumatism, were able to leave the hospital at the end of the first week of their residence there, very frequently at the end of their second week, whereas it was a rare occurrence if any stayed beyond that period.

The medical staff of the hospital consisted of three physicians; it was my lot, of course, to be the junior. The senior was an old gentleman of about seventy, who had, during an earlier part of his life, becn a surgeon in the army; the other was a gentleman of about forty-fire-he was a good scholar, and, in many respects, a good practical physician. Mty practice of giving bark in acute rheumatism was duly comniunicated to both ; but, to my considerable disappointment and regret, neither of them adopted it. The consequence of this was, that their patients remained pale, emaciated, and crippled pensioners on the resources of the hospital for many weeks after mine of the same dates of admission were dismissed cured, and had returned to their homes quite competent to resume their ordinary occupations. My private patients in the town and neighbourhood were treated precisely on the same system of medical management with the patients of the hospital, and with the sume result, with sequence of its proring, at least, a temporary exception, I feel it my duty especially to notice. The case in question was that of a young gentleman of eighteen years of age, the son of a wealthy factor resident in Sheffield, who had been somewhat severely handled by a rheumatic fever of considerable intensity for about ten days or a fortnight before I was consulted in his case. My medical friend, who attended him in the first instance, had never heard of Dr. Haygarth's practice of exhibiting the cinchona in acute rheumatism; but upon my explanation and strong recommendation of that practice, he immediately concurred with me in the propriety of adopting it. The patient, at that period, complained not only of pain of one or more of the larger joints, but also of severe pains on both sides of his chest. My friend had already bled him very freely, both generally and by the application of leeches to the affected parts; and, therefore, after premising a purgative of calomel and jalap, he was placed, with as little loss of time as possible, on the bark treatment. It was quite a surprise to my friend to observe how soon the case improved under its use. The patient's excessive perspirations diminished; his painful and oppressed respirations were performed with more facility; and his swoonings and faintings became, in a short time, much less frequent; in short, he got better from day to day, until he recovered a very tolerable state of health. By the great violence and complication of his case, however, his constitution was left considerably impaired in power, and his heart remained for some time afterwards incompetent to carry on the business of its office without some positive irregularity, although he had ceased to be tormented with the alarming palpita. tions which had greatly distressed and terrified him during the height of his paroxysm of acute rheumatism. At a subsequent period, after I had myself migrated to the metropolis, I had the good fortune to meet with my quondam patient accidentally in London; it was in our great thoroughfare of Fleet-street. I was much pleased to see him, as he exhibited the appearance of very strong health. I felt exceedingly desirous of acquaintiug myself with the particulars of his casc, and especially with the state of his heart's action, and we accordingly retired to an adjoining hotel to insure a convenient opportunity for that purpose. He had entirely got rid of all inregularity of the pulse. When I first saw him, the subject of his attack of acute rheumatism, at Sheffield, he was reduced to a state of considerable emaciation, and his heart palpitated dreadfully. When I met him on this occasion, he presented the figure of a well-grown, portly young gentleman, of about seven or eight and twenty, and his heart was remarkable for the healthfulness and regularity of its 
movements, as far, at least, as I could judge by the feel of his pulse and applying my hand to his chest. At that period Laennec had not published his important work on the uses of the stethoscope. That the usual results of rheumatism of the heart, as the metastasis, now supposed, had probably even then been designated by Dr. Wells, were not perfectly and permanently established in the above case, there can, I think, be no doubt. But how far they were prevented by the use of the bark, which had been exhibited during a comparative early period of the acute attack of the malady, I dare not venture to assert. I am aware that there are but very few cases on record of equally perfect recoveries from very severe cases of acute rheumatism, accompanied by the extreme symptoms usually considered to indicate the complication of acute rheumatic fever with rheumatism of the heart. Such recoveries are unquestionably of most unfrequent occurrence.

During my residence in London, I have never essentially departed from the practice which I adopted after much deliberation in the country; nor have I encountered a case of acute rheumatism which has not, upon the whole, speedily yielded to the measures resorted to. My patients in London have most frequently been an occasional pupil in my own class, but much oftener the sons and servants of families whom I might be attending professionally in my own department, at or shortly after the attacks of acute rheumatism, which I was requested also to see and prescribe for: from this explanation a good reason may be tolerably easily inferred, why I must have been generally consulted at an early period of the disease ; a circumstance of no small importance in the calculation of an active practitioner. Of the class of pupils I may be permitted briefly to sketch the particulars of one case which gave me unmixed satisfaction at the conclusion of my attendance, although the subject of it yielded to a fate which greatly excited my sorrow and sympathy in the course of a few years subsequently. Mr. G., one of my pupils, the son of a clergyman, from Wales, a young gentleman of about eighteen, was reported to me by one of his fellow-pupils as having become the subject of acute rheumatism. He was of a delicate constitution, of spare habit, narrow-chested, and of a sanguineous temperament. I accompanied his friend forthwith to see him, and he was bled to the amount of about twenty ounces in my presence. A prescription was left at his lodgings for an emetic, which was directed to be administered to him as soon as it could be procured; after which he was desired to take a purgative, consisting of calomel and jalap, in the course of four or five hours subsequently to the action of the emetic. On the following day leeches were applied to the ankles of the affected leg, and on the day succeeding a greater number to the knees of the other leg, whither the pain had receded during the intervening night. These depletions having been duly attended to, my young friend was placed on the cinchona treatment for about a week. His fever abated rapidly, his prow fuse perspirations ceased gradually to annoy him, the pains of his joints insensibly diminished from day to day, and he was able to join the class apparently in good health in less than a fortnight from his indisposition. During its brief continuance he was in no degree the subject of any affection of the chest. At the conclusion of my course of lectures he called upon me to take leave, when he ap. peared to me to be in possession of his ordinary state of moderately good health.

Some years afterwards I was casually in * formed by one of my oldest professional friends, that my quondam pupil had become his son-in-law, and subsequently his partner. After the lapse of some few more years, I was again informed by the same gentleman that his son-in-law had died the year before of a disease of the heart, which, in the lan. guage of that period, he called angina pectoris. He further stated, that about a twelve. month before his death he had been the subject of a severe attack of rheumatic fever of many weeks' duration, from the effects of which he never properly recovered.

Thus bereft of his son-in-law, his professional partner, and the husband and protector of his only daughter, he soon after, with his daughter and grandchild, retired from the cares of his profession to spend the remainder of his days in a pleasant village in the county of Kent.* All that I ventured to ask of my old friend was, Whether he was old enough to remember the practice of the late $\mathrm{Dr}$. Saunders, who prescribed bark in acute rheumatism? And receiving an answer in the negative, without further remark, I con. cluded that his son-in-law had had no cinchona prescribed for him since he was my own patient on the occasion already referred to. All the inference which, perhap:, it might be perfectly logical to deduce from the above facts of poor G.'s case, appears to be that, when the bark was opportunely prescribed, and in proper quantities after other previous measures of adequate activity and importance, the patient escaped becoming the victim of rheumatism of the heart; but that when attacked again by the same disease, after the lapse of six or seven years from the date of his former indisposition, when no

* Private authentication of the above case. The subject of it was Mr. Griffiths, a young gentleman from Wales, but from what county I have now no means of ascertaining. He married the daughter of Mr. Anderson, then a general practitioner of Fleet-street, who, at the time above alluded to, retired to, and now resides at, the pleasant village of West Wickham, in Kent. 
bark was prescribed, and when the malady was probably treated with antimonials and other sudorifics, on principles then prevalent in the profession, and possibly without being accompanied in other respects by measures of adequate vigour, the case terminated in the destruction of the patient's life.

Upwards of twenty years ago I was deputed by my late friend, Dr. Sims, to attend a lady in his connection, who resided in Queen-square, Bloomsbury. As by some accident $I$ have lost the particulars essential to the proper authentication of the case to be noticed, I shall merely state that one of the sons of the family, a young gentleman of about fourteen years of age, came unexpectedly home from school, the subject of a severe rheumatic fever, complicated from an early period, if not from the beginning of the attack, with intensely-painful affections of more than one of the viscera of the thorax. He was bled once, and largely for his age, as soon as I saw him; I can well remember, for it really is a matter of memory, that he completely fainted ; he was then ordered an emetic of tartarised autimony and powder of ipecacuhana, after which he took, early next morning, a purgative of calomel and jalap ; as soon afterwards as possible he was placed on the cinchona treatment, which has already been sufficiently detailed in the description of several of the preceding cases. In the course of three or four days, there was an entire remission of all the painful symptoms both of the chest and of the inferior extremities. Without positively assuming the fact that this most alarming case (for the symptoms of the first day or two were extremely tempestuous and complicated) amounted to one of rheumatism of the heart; I confess that I was not a little pleased that it yielded rapidly to the measures and the remedies prescribed.

The only remaining case I shall feel it my duty to detail on the present occasion was a striking example of a severe rheumatic fever, of short duration indeed, produced by excessive excitement of the arterial system. The subject was one of my own sons. When between seven and eight years of age, $I$ indulged him with a journey to Wales, in company with myself, to see his grandfather. It took us two days to perform a journey of two hundred and twelve miles, sleeping the intermediate night at Gloucester. On arriving the second night at Carmarthen, my young companion was greatly fatigued and exhausted. On the following morning, however, he awoke quite refreshed, and was so delighted with the welcome of my friends, and the thousand novelties that presented themselves to his astonished attention, that he became exceedingly excited. On the third day after our arrival, I was induced by my much-valued friend, Mrs. Picton, of Iscoed (the Rev. Edward Picton was the brother and heir of the late Sir Thomas Picton), to consent to give him leave to stay two or three days as her visitor, she engaging as an inducement to my acceding to her proposal, that she would take very good care of him, which, indeed, I did not donbt. After indulging, beyond all measure, his natural mobility, amidst the beautiful rusticities and sceneries, extensive gardens, large dairy farm, stables, cowhouses, \&c., of Iscoed, to an absolute satiety of pleasure, he went to bed not less fatigued than on the two preceding nights. He had, probably, moreover, exposed himself, during his perambulations about Mr. Picton's grounds, to the action of a north-east wind, which, although in the month of August, had blown somewhat keenly on that day, for, in the course of the night, he was seized with a severe pain of his ankle-joints, and also of one knee ; in short, he became the subject of a smart attack of acute rheumatism. Mrs. Picton, not a little alarmed at what occurred, sent him to his grandfather's in an easy covered car, stretched his whole length on a soft bed, early in the forenoon of the following day, in order that I might have the opportunity of treating his case as I might think best without loss of time. His extraordinary mobility and restlessness had ceased for want of ability to move; but his arterial system was prodigiously excited. Brought to $m y$ father's house, under the care of my friend, $\mathrm{Mr}$. Rose Picton, then a student of medicine, I availed myself of the assistance of that gentleman to bleed him, without a moment's delay, and he was bled accordingly, ad deliquium. I had no medicines by me, which $I$ am now rather glad of, inasmuch as it obliges me to make my friend, Mr. Jenkins, senior surgeon of Carmarthen, a party to the authentication of the case. After the bleeding, I sent forthwith to that gentleman's establishment to procure such medicines as I considered necessary for immediate exhibition. The emetic, the purgative, and the cinchona powders, were consecutively exhibited with as little loss of time as possible. As I know that my good old friend, Mr. Jenkins, has been a reader of THE LANCET for many years, and most probably from the commencement of its publication, $I$ need not now go into a detail of the adopted practice, with which the reader is also at length become familiarly acquainted. My boy was well enough to travel with me back again to London, in the course of about a week from the commence. ment of his rheumatic fever.

In a future communication, I shall have to offer some reasons for my preference of the cinchona practice in the treatment of acute rheumatism to all other modes of management that I have seen adopted.

\section{David D. Davis.}

17, Russell-place, Fitzroy-square,

Dec. 31, 1840. 